\title{
CAN SDAI REMISSION BE PREDICTED IN PATIENTS WITH ESTABLISHED RHEUMATOID ARTHRITIS TREATED WITH ANTI-TNF AGENTS?
}

\author{
Cristina Pomirleanu ${ }^{1,2}$, Alexandra Jitaru ${ }^{2,3}$, Raluca Maxim $^{2}$, Codruta Belibou ${ }^{2,4}$, Codrina Ancuta ${ }^{1,2}$ \\ ${ }^{\prime}$ Rheumatology and Rehabilitation Discipline, Grigore T. Popa University of Medicine and Pharmacy, Iasi \\ ${ }^{2}$ Rheumatology 2 Department, Clinical Rehabilitation Hospital, Iasi \\ ${ }^{3}$ Grigore T. Popa University of Medicine and Pharmacy, Iasi \\ ${ }^{4}$ Research Department, Clinical Rehabilitation Hospital, Iasi
}

\begin{abstract}
Objective. To identify predictors for Simplified Disease Activity Index (SDAI) remission in established rheumatoid arthritis (RA) and to develop a predictive score for remission.

Methods. Prospective 12-month observational study in ninety active RA receiving their first TNF- $\alpha$ inhibitor. Standard assessments consisted of disease activity scores (DAS28-ESR, SDAI) and immune parameters (total rheumatoid factor, RF; IGA-RF; anti-cyclic citrullinated peptide antibodies, ACPA). The primary outcome measure was SDAl remission $(\leq 3.3)$ at 12 months.

Univariate and multivariate logistic regression models were used to estimate association between baseline variables and SDAI remission.

Results. $39.7 \%$ RA achieved remission, while $56.8 \%$ low disease activity. Significant association between SDAI remission and RA-onset before $50(p=0.000)$, history $<5$ years $(p=0.000)$, stage $(p=0.000)$, class I and II Steinbroker functional status $(p=0.022), \mathrm{HAQ}-\mathrm{DI} \leq 2(p=0.034), \mathrm{CRP} \leq 20 \mathrm{mg} / \mathrm{l}(p=0.041), \mathrm{IgA}-\mathrm{RF} \leq 20 \mathrm{IU} / \mathrm{ml}$ $(p=0.002), A C P A \leq 40 \mathrm{IU} / \mathrm{ml}(p=0.047)$, concomitant DMARDs $(p=0.003)$ were identified. Four parameters independently predicted 12-month remission (age at onset under 50 , RA duration $<5$ years, ACPA $\leq 40 \mathrm{IU} / \mathrm{ml}$, $\mathrm{IgA}-\mathrm{RF} \leq 20 \mathrm{IU} / \mathrm{ml}$ ) as demonstrated by multivariate logistic regression $(p<0.05)$, making correct prediction in $84.4 \%$ patients. Furthermore, the remission score correctly classified $90.6 \%$ RA, while the transformed simplified version up to $89.4 \%$ cases. Gender, clinical parameters and ESR were not predictors for treatment response $(p>0.05)$. Conclusion. SDAI remission can be predicted in established RA using a score based on age at onset, disease duration, titers of ACPA and RF isotype A. Such a simplified score may help clinicians to manage remission in RA patients according to the current treatment guidelines.
\end{abstract}

Keywords: anti-TNF agents, established rheumatoid arthritis, predictors, remission, SDAI

\section{INTRODUCTION}

Rheumatoid arthritis (RA) is a chronic systemic inflammatory disease of a still unknown etiology, but a complex and dynamic pathophysiology, hypothesized to develop in genetically susceptible host (1).

It has been shown that early intervention with disease-modifying antirheumatic therapies (non-biologic and biologic DMARDs) represents the optimal care of patients with RA and gives the best opportunity for attempting to achieve disease remission (2).

However, predicting the course of a particular case of RA at the outset of a new treatment option remains challenging, although different predictors of an unfavorable prognosis in terms of joint damage and disability have already been recognized (3).

Remission is considered a disease status, not a simple change or transition, meaning generally the absence of disease activity and predicting the best clinical, functional and structural outcomes. Nevertheless, increasing numbers of patients reaching remission as well as abundance of Boolean and indexbased remission definitions (Disease Activity Score DAS28, Clinical Disease Activity Index CDAI, and Simplified Disease Activity Index SDAI) have suggested the need for a uniform definition of RA remis-

Correspondence address:

Codrina Ancuta, Rheumatology 2 Department, Clinical Rehabilitation Hospital, 14 Pantelimon Halipa St., Iasi

E-mail: codrina_ancuta@yahoo.com 
sion such as the new ACR/EULAR provisional definition of RA remission $(4,5,6)$.

SDAI is a simple sum of five outcome measures counting tender and swollen joints, patient and physician global RA assessment as well as C-reactive protein (CRP). Different cut-off levels are actually validated for SDAI as follows: 3.3 indicating remission (REM), 11 indicating low disease activity (LDA), 26 moderate disease activity (MDA), while a value higher than 26 is commonly used for defining high disease activity (HDA) $(7,8)$.

Several research papers $(9,10,11,12)$ have already indicated that SDAI may be successfully used in clinical practice instead of other validated indexes in order to define patients achieving remission in various RA settings.

We performed a prospective study aiming to identify predictors for SDAI remission in patients with established RA treated with TNF inhibitors and to develop a prediction score for remission.

\section{PATIENTS AND METHODS}

Ninety consecutive patients fulfilling the 1987 ACR classification criteria for RA, with established severe active disease (DAS28 $\geq 5.1$, SDAI $\geq 26$ ) requiring biologics were enrolled in a prospective observational 12-months study. The inclusion and exclusion criteria were defined according to the recommendations of the Romanian Society of Rheumatology that calls for anti-TNFs in highly active disease with suboptimal response to previous therapy with at least two synthetic Disease Modifying Anti-Rheumatic Drugs (DMARDs) including methotrexate (13).

Patients were assigned to one of three treatment groups according to the decision of their treating rheumatologist, 33 RA further receiving adalimumab, 30 etanercept and 27 infliximab. Concomitant non-biological DMARDs (methotrexate, leflunomide, sulfasalazine, hydroxycloroquine) were allowed, while oral corticosteroids $(\leq 10 \mathrm{mg} /$ day prednisone or equivalent) only if maintained at a stable dose within 12 weeks prior to enrollment.

Standard assessments consisted of 28 joint count, patient reported outcomes, laboratory specimens for CRP, erythrocyte sedimentation rate (ESR), total rheumatoid factor (RF) and IgA-RF isotype, anticyclic citrullinated peptide antibodies (ACPA), as well as disease activity scores (DA28-ESR, SDAI). Total RF was measured by latex immunoturbidimet- ric method (cut-off value $14 \mathrm{IU} / \mathrm{ml}$ ), IgA-RF by ELISA (cut-off $20 \mathrm{IU} / \mathrm{ml}$ ), and IgG-ACPA by FluoroImmuno-Enzymatic (FEIA) assay (cut-off $10 \mathrm{IU} /$ $\mathrm{ml})$.

The main outcome was SDAI remission at 12 months. Treatment response was measured by EULAR-DAS28 criteria (14).

Local Ethical Committee approval and written informed consent were obtained prior the study.

\section{STATISTICAL ANALYSIS}

The baseline characteristics were analyzed by Mann-Whitney U test for continuous variables, whereas chi square was used for categorical variables.

Univariate and multivariate logistic regression expressed as odds ration (OR), with $95 \%$ confidential interval (CI), and 2-tailed ,p“ were used to estimate the association between potential predictors and SDAI remission.

We created several models based on different (demographic, clinical, biological) variables aiming to investigate their influence on disease outcome (SDAI remission) after 12 months of biological therapy. We considered remission as a binary variable and, subsequently, we constructed binary logistic regression models using different parameters as predictors. We have applied the logistic regression Forward LR model; the innitial step without any predictor, further steps of the algorithm adding one by one different predictors.

Variables included in the logistic regression model have been identified to be statistically significant $(\mathrm{p}<0.05)$ by initial individual logistic regression (univariate analysis) performed for each parameter potentially involved as a predictor for therapeutic response

To obtaine a remission score we considered the mathematical formula $(\beta 1 \times \mathrm{V} 1)+(\beta 2 \times \mathrm{V} 2)+(\beta 3$ $\times V 3) \ldots+\alpha+e$, where $\beta$ is the regression coefficient of the variable, $V$ the independent variable, alpha the constant and e the error. To evaluate the predictive power of the score we constructed a receiver operating characteristic (ROC) curve, the area under this curve measuring the concordance of predictive values with current outcome.

Finally, we developed a simplified remission score based on factors obtained in the regression analysis. All statistical analysis was carried out with SPSS16, with ,p“ $<0.05$. 


\section{RESULTS}

\section{Patients and remission rates}

A cohort of long-standing RA, mainly female $(81.1 \%)$, with an average age $55.56 \pm 10.75$ years, average disease duration $10.9 \pm 6.2$ years, mean DAS28 $7.50 \pm 0.40$ and mean SDAI $51.38 \pm 5.42$ were enrolled in the study. Baseline characteristics (Table 1) did not differ significantly between study groups, except the ESR $(\mathrm{p}=0.009)$.

\section{Regression analysis}

\section{Predictors}

All variables were independently analyzed by univariate logistic regression; only nine parameters were statistically significant (chi squared, $p<0.05$ ) and used further as predictors for remission: age at onset, RA duration and stage, functional class and HAQ-DI, CRP, IgA-RF, ACPA, and concomitant DMARDs.

Statistical analysis showed significant association between SDAI remission and onset before 50 years (OR: 5.25, 95\% CI 2.27-12.14; $\mathrm{p}=0.000)$, RA duration under 5 years (OR:5.53, 95\% CI 2.40$12.75 ; \mathrm{p}=0.000$ ), first and second RA stage (OR:4.22, 95\% CI 1.99-8.94; $\mathrm{p}=0.000)$, functional status as re- flected by Steinbroker class I and II and HAQ-DI $\leq 2$ (OR:2.67, 95\% CI 1.07-6.68; $\mathrm{p}=0.022$; OR:2.39, 95\% CI 1.02-5.60; $\mathrm{p}=0.034$, respectively), CRP $\leq 20$ $\mathrm{mg} / \mathrm{l}$ (OR:1.75, 95\% CI 0.81-3.73; $\mathrm{p}=0.041)$, IgA$\mathrm{RF} \leq 20 \mathrm{IU} / \mathrm{ml}$ (OR:5.76, 95\% CI 1.43-23.23; $\mathrm{p}=0.002)$, ACPA $\leq 40 \mathrm{IU} / \mathrm{ml}$ (OR:1.99, 95\% CI 0.954.17; $\mathrm{p}=0.047$ ) and concomitant DMARDs (OR:5.50, 95\% CI 1.36-22.13; $\mathrm{p}=0.003)$. Gender, clinical individual parameters and ESR were not predictors for treatment response in the total study population $(\mathrm{p}>0.05)$.

Moreover, multivariate logistic regression demonstrated that only age under 50 at onset, symptoms duration up to 5 years, baseline ACPA $\leq 40 \mathrm{IU} / \mathrm{ml}$ and $\mathrm{IgA}-\mathrm{RF} \leq 20 \mathrm{IU} / \mathrm{ml}$ remained independently associated with SDAI remission at 12 months (Table 2), making correct prediction in $84.4 \%$ cases (Hosmer and Lemeshow test fitting $\lambda^{2}=3.695, \mathrm{p}=0.718$ and Cox and Snell R2 $=0.432$ ). The use of other factors does not improve the prediction level in our patient population.

\section{Multivariate remission score}

Taking into account the model of the remission score recently proposed by Ma et al. in early RA

TABLE 1. Demographics, clinical and biological characteristics of RA patients at baseline

\begin{tabular}{|c|c|c|c|c|c|}
\hline \multirow[b]{2}{*}{ Parameter } & \multirow[b]{2}{*}{$\begin{array}{l}\text { Total } \\
\mathrm{n}=90\end{array}$} & \multicolumn{3}{|c|}{ Treatment subgroups } & \multirow[b]{2}{*}{ p } \\
\hline & & $\begin{array}{c}\text { Adalimumab } \\
n=33\end{array}$ & $\begin{array}{c}\text { Etanercept } \\
n=30\end{array}$ & $\begin{array}{c}\text { Infliximab } \\
n=27\end{array}$ & \\
\hline Age (years)* & $55.56 \pm 10.75$ & $53.64 \pm 11.93$ & $55.13 \pm 9.99$ & $58.37 \pm 9.80$ & 0.231 \\
\hline Women** & $73(81.1 \%)$ & $29(87.9 \%)$ & $21(70 \%)$ & $23(85.2 \%)$ & 0.161 \\
\hline RA stage $3 / 4^{* *}$ & $67(74.4 \%)$ & $24(72.7 \%)$ & $23(76.7 \%)$ & $20(74.1 \%)$ & 0.899 \\
\hline Concomitant CS** & $50(50.6 \%)$ & $22(66.7 \%)$ & $17(56.7 \%)$ & $11(40.7 \%)$ & 0.134 \\
\hline MTX** & $23(25.6 \%)$ & $5(15.2 \%)$ & $10(33.3 \%)$ & $8(29.6 \%)$ & \multirow{3}{*}{0.160} \\
\hline LEF** & $28(31.1 \%)$ & $8(24.2 \%)$ & $7(23.3 \%)$ & $13(48.1 \%)$ & \\
\hline Others DMARDs** & $39(43.3 \%)$ & $20(60.6 \%)$ & $13(43.3 \%)$ & $6(22.2 \%)$ & \\
\hline TJC $(28)^{*}$ & $18.53 \pm 2.82$ & $18.15 \pm 3.01$ & $19.10 \pm 3.29$ & $18.36 \pm 1.77$ & 0.154 \\
\hline $\operatorname{SJC}(28)^{*}$ & $11.81 \pm 2.42$ & $11.67 \pm 2.52$ & $12.20 \pm 2.95$ & $11.52 \pm 1.41$ & 0.081 \\
\hline DAS28-ESR* & $7.50 \pm 0.40$ & $7.46 \pm 0.44$ & $7.42 \pm 0.33$ & $7.63 \pm 0.40$ & 0.382 \\
\hline SDAI & $51.38 \pm 5.42$ & $50.86 \pm 5.87$ & $51.06 \pm 8.30$ & $51.39 \pm 3.83$ & 0.287 \\
\hline HAQ-DI $(0-3)^{*}$ & $2.02 \pm 0.33$ & $2.03 \pm 0.33$ & $2.03 \pm 0.31$ & $2.00 \pm 0.34$ & 0.387 \\
\hline $\operatorname{ESR}(\mathrm{mm} / 1 \mathrm{~h}) * * *$ & 66.61 & 68.58 & 57.07 & 75.48 & 0.009 \\
\hline CRP (mg/liter)*** & 36.43 & 36.71 & 39.30 & 32.64 & 0.254 \\
\hline $\mathrm{RF}(\mathrm{IU} / \mathrm{ml}) * * *$ & 228.73 & 232.57 & 189.61 & 270.60 & 0.245 \\
\hline $\operatorname{IgA-RF}(\mathrm{IU} / \mathrm{ml}) * * *$ & 41.05 & 36.28 & 41.26 & 40.71 & 0.267 \\
\hline ACPA (IU/ml)*** & 99.3 & 114.36 & 76.24 & 107.20 & 0.578 \\
\hline
\end{tabular}

ACPA - anti-cyclic citrullinated peptide antibody; CRP - C-reactive protein; DAS28 - Disease Activity Score; DMARDs - Disease Modifying Antirheumatic Drugs; ESR - erytrocyte sedimentation rate; HAQ-DI - Health Assessment Questionnaire Disability Index; LEF - leflunomide; MTX - methotrexate; CS - corticosteroids; RA - rheumatoid arthritis; RF - rheumatoid factor; SJC - swollen joint count; SDAI - Simplified Disease Activity Index; TJC - tender joint count; * - mean \pm SD; ** $-\mathrm{n}(\%) ; * * *-$ mean

After 12 months, 50 patients (56.8\%) achieved LDA, and 35 (39.7\%) were in remission according to SDAI criteria. These frequencies correspond to the following distribution in treatment group analysis: $42.4 \%$ remission for adalimumab, $36.6 \%$ for etanercept and $40 \%$ for infliximab. 
TABLE 2. Forward Logistic Regression (LR) model for SDAl remission

\begin{tabular}{|c|c|c|c|c|c|c|c|}
\hline & & B & S.E. & Wald & df & Sig. & $\operatorname{Exp}(B)$ \\
\hline \multirow[t]{2}{*}{ Step $1^{a}$} & Onset of disease $\leq 5$ years & -2.526 & .542 & 21.712 & 1 & .000 & .080 \\
\hline & Constant & 1.427 & .321 & 19.710 & 1 & .000 & 4.167 \\
\hline \multirow[t]{3}{*}{ Step $2^{b}$} & Onset of disease $\leq 5$ years & -2.481 & .599 & 17.154 & 1 & .000 & .084 \\
\hline & ACPA $\leq 40 \mathrm{IU} / \mathrm{ml}$ & -1.938 & .578 & 11.253 & 1 & .001 & .144 \\
\hline & Constant & 2.186 & .454 & 23.157 & 1 & .000 & 8.895 \\
\hline \multirow[t]{4}{*}{ Step $3^{c}$} & Age $\leq 50$ years & -1.664 & .627 & 7.043 & 1 & .008 & .189 \\
\hline & Onset of disease $\leq 5$ years & -2.041 & .631 & 10.453 & 1 & .001 & .130 \\
\hline & ACPA $\leq 40 \mathrm{IU} / \mathrm{ml}$ & -1.980 & .612 & 10.469 & 1 & .001 & .138 \\
\hline & Constant & 2.666 & .539 & 24.463 & 1 & .000 & 14.383 \\
\hline \multirow[t]{5}{*}{ Step $4^{d}$} & Age $\leq 50$ years & -1.528 & .652 & 5.502 & 1 & .019 & .217 \\
\hline & Onset of disease $\leq 5$ years & -2.243 & .689 & 10.609 & 1 & .001 & .106 \\
\hline & RF isotype $A \leq 20 \mathrm{IU} / \mathrm{ml}$ & -1.737 & .763 & 5.185 & 1 & .023 & .176 \\
\hline & ACPA $\leq 40 \mathrm{IU} / \mathrm{ml}$ & -1.632 & .653 & 6.247 & 1 & .012 & .195 \\
\hline & Constant & 3.759 & .821 & 20.948 & 1 & .000 & 42.892 \\
\hline
\end{tabular}

ACPA - anti-cyclic citrullinated peptide antibody; RF - rheumatoid factor.

(15), we generated a multivariate remission score using the coefficients derived from multivariate logistic regression.

Our remission score was $(-1.528 \mathrm{x}$ age $\leq 50$ years $)$ $+(-2.243 \mathrm{x}$ onset of disease $\leq 5$ years $)+(-2.243 \mathrm{x}$ $\mathrm{RF}$ isotype $\mathrm{A} \leq 20 \mathrm{IU} / \mathrm{ml})+(-1.632 \mathrm{x}$ anti-CCP $\leq 40$ $\mathrm{IU} / \mathrm{ml})+3.759+0.821$.

We calculated the score for each patient: higher values suggested higher probability that a specific patient will achieve SDAI remission after 12 months of anti-TNFs. The area under the ROC curve was 0.90 (Figure 1A), meaning that the score correctly classified $90.6 \%$ of patients, with high sensitivity (84.8\%) but low specificity (19.3\%).

\section{Simplified remission score}

As the proposed score for predictings remission is time consuming and possible not feasible in daily practice, we created a simplified version in which we assigned either zero or one point for each of the above mentioned parameters: one point for age at onset before 50, one point for symptom duration under 5 years, one point for IgA-RF $\leq 20 \mathrm{IU} / \mathrm{ml}$ and one point for ACPA $\leq 40 \mathrm{IU} / \mathrm{ml}$. Thus, our simplified remission score offered values ranging from 0 to 4 for all above significant remission predictors.

The transformed scores revealed a significant high correlation between simplified and multivariate remission scores (Spearman's test: $r=0.99, p<0.05$ ).

The area under ROC curve was 0.89 (figure 1B), the score correctly classifying up to $89.4 \%$ of patients with established RA, with a high sensitivity (87.9\%) but poor specificity $(26.3 \%)$.
Furthermore, we evaluated the likelihood of achieving SDAI remission as well as LDA and MDA.

The results are shown in figure 2, 15.6\% patients had a simplified remission score of 3 and $10 \%$ a remission score of 4 , with a high chance of remission at 12 months ( $78.6 \%$ and $100 \%$ respectively). On the other hand, low scores as defined by values of 0 and 1 were seen in $23.3 \%$ and $27.8 \%$ of RA, respectively, and were not associated with SDAI remission.

\section{DISCUSSION}

We have hypothezed that SDAI remission could be predictied in patients with active established RA treated with TNF inhibitors by using a simplified validated index (SDAI) and we have, finally, demonstrated that several predictors are currenly relevant for patients matching the inclusion criteria. Moreover, we proposed a prediction model for SDAI remission in established RA based on four parameters (age of patient at RA onset, disease duration, IgA isotype of RF and ACPA levels) that effectively classified up to $80 \%$ of cases as achieving remission. That means patients with a disease onnset before the age of 50, with a RA history lower than 5 years, low levels of IgA-RF $(<20 \mathrm{IU} / \mathrm{ml})$ and ACPA $(<40 \mathrm{IU} /$ $\mathrm{ml}$ ) at baseline, before starting the biologic DMARD were most likely to achieve SDAI remission over 12 months of a TNF blocking agent (infliximab, etanercept, adalimumab).

Reaching remission is a desirable status even in patients with longstanding established RA $(4,6,10,11)$. Moreover, LDA is considered a good alternative op- 


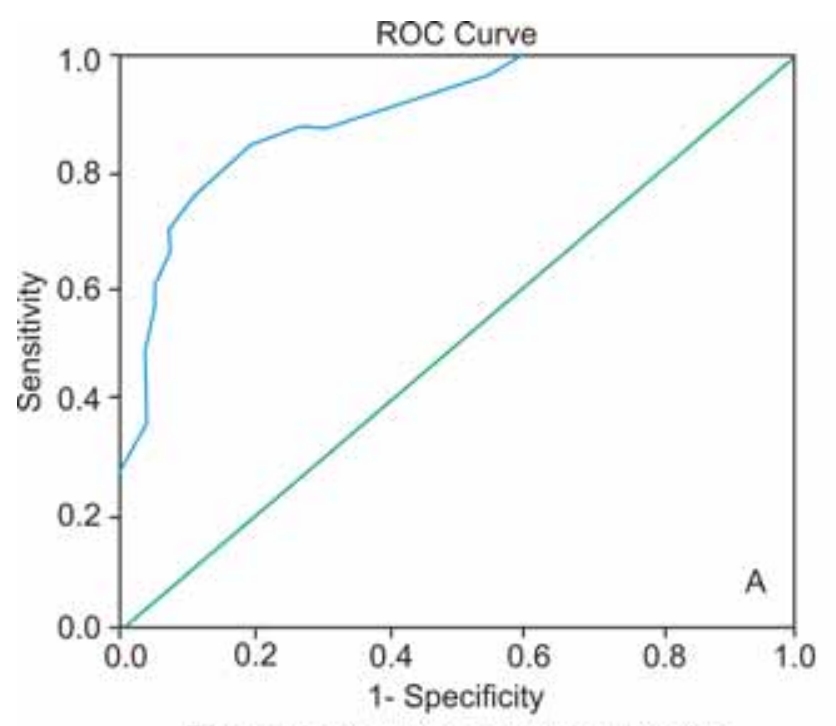

Diagonal segments are produce by ties

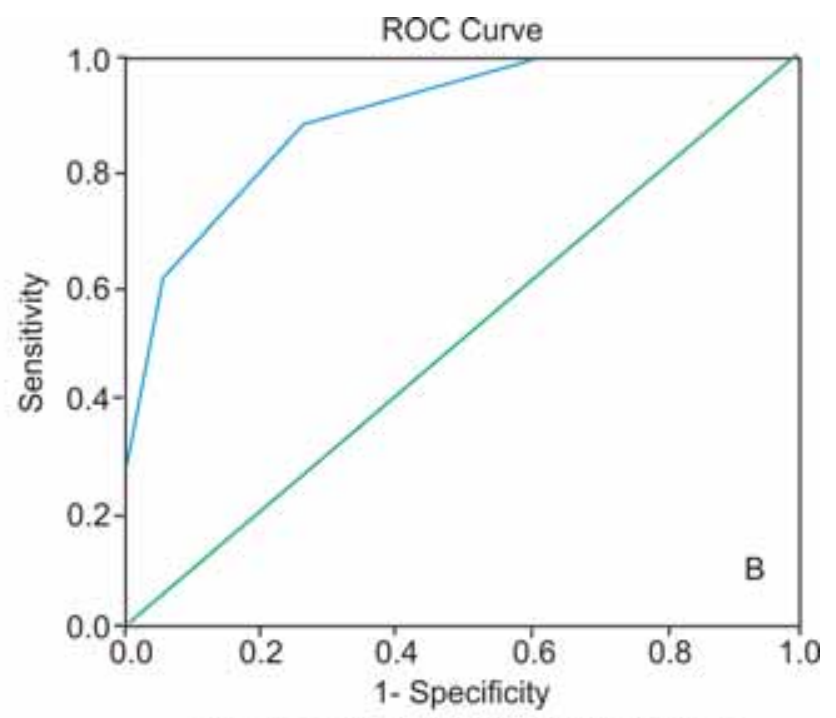

Diagonal segments are produce by ties

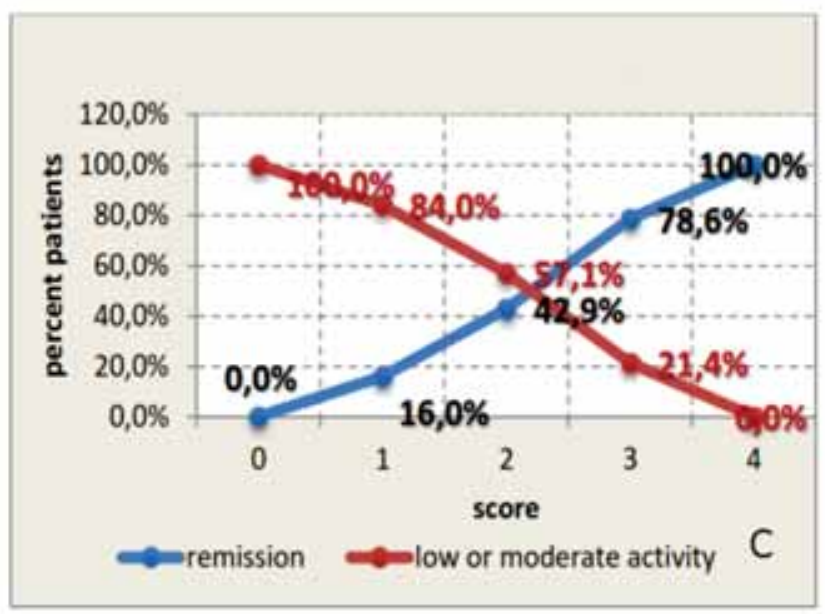

FIGURE 1 A. ROC curve for the multivariate remission score; B. ROC curve for the simplified remission score; C. The ability of the simplified remission score to predict disease status at 12 months

tion in patients in whom remission cannot be reached based on varia reasons ranging from comorbidities, contraindications to negative prognostic factors $(10,11)$.

In our study we have particularly focused on the SDAI remission as, to our knowledge, this topic was only occasionally directed especially in established RA. We considered SDAI remission at a single time point (12 months) as the individual condition to evaluate the response to biologic treatment and we defined four independent predive factors: age, symptoms duration, and IgA-RF and ACPA levels as well. Interestingly, we did not find any clinical parameter or acute phase reactants involved in SDAI remission prediction.

Furthermore, as the multivariate remission score could be considered too laborious for routine clinic, we provided a simplified score, intended to correctly identify future responders who can be given additional treatment with TNF inhibitors in daily practice.

As our predictive model of SDAI remission in established RA receiving anti-TNF therapy was the result of a small cohort of patients, the model should be validated in larger cohorts and the concept extended to other RA clinical settings and for other biologic and non-biologic DMARDs.

\section{CONCLUSION}

SDAI remission is predictible in biological-naive established RA using a score based on age, disease duration, baseline ACPA and IgA-RF. Such a simplified score may help clinicians to manage remission in RA patients according to the current treatment guidelines. 


\section{REFERENCES}

1. Mease P.J. (2011) The potential roles for novel biomarkers in rheumatoid arthritis assessment. Clin Exp Rheumatol 29(3):567-74s

2. Smolen J.S., Aletaha D., Bijlsma J.W.J., Breedveld F.C., Boumpas D., Burmester G., et al. (2010) Treating rheumatoid arthritis to target: recommendations of an international task force. Ann Rheum Dis 69:631-37

3. van Tuyl L.H., Felson D.T., Wells G., Smolen J., Zhang B., Boers M. (2010) Evidence for predictive validity of remission on long-term outcome in rheumatoid arthritis: a systematic review. Arthritis Care Res (Hoboken) 62(1):108-17

4. Shammas R.M., Ranganath V.K., Paulus H.E. (2010) Remission in rheumatoid arthritis. Curr Rheumatol Rep 12:355-62

5. Pinals R.S., Masi A.T., Larsen R.A. (1981) Preliminary criteria for clinical remission in rheumatoid arthritis. Arthritis Rheum 24:13-8

6. Felson D.T., Smolen J.S., Wells G., Zhang B., van Tuyl L.H., Funovits J., et al. (2011) American College of Rheumatology/ European League Against Rheumatism provisional definition of remission in rheumatoid arthritis for clinical trials. Arthritis Rheum 63:573-86

7. Aletaha D., Smolen J.S. (2009) The Simplified Disease Activity Index and Clinical Disease Activity Index to monitor patients in standard clinical care. Rheum Dis Clin North Am 35:759-72

8. Aletaha D., Martinez-Avila J., Kvient T.K., Smolen J.S. (2012) Definition of treatment response in rheumatoid arthritis based on simplified and the clinical disease activity index. Ann Rheum Dis 71:1190-96

9. Smolen J.S., Breedveld F.C., Schiff M.H., Kalden R., Emery P., Eberl G., et al. (2003) A simplified disease activity index for rheumatoid arthritis for use in clinical practice. Rheumatology 42:244-57
10. Sokka T., Hetland M.L., Makinen H., Kautiainen H., HørslevPetersen K., Luukkainen R.K., et al. (2008) Remission and rheumatoid arthritis. Data on patients receiving usual care in twenty-four countries. Arthritis Rheum 58:2642-51

11. Gaujoux-Viala C., Mouterde G., Baillet A., Claudepierre P., Fautrel B., LeLoët X., et al. (2012) Evaluating disease activity in rheumatoid arthritis: Which composite index is best? A systematic literature analysis of studies comparing the psychometric properties of the DAS, DAS28, SDAI and CDAl. Joint Bone Spine 79(2):149-55

12. Balsa A., de Miguel E., Castillo C., Peiteado D., Martı́n-Mola E. (2010) Superiority of SDAI over DAS-28 in assessment of remission in rheumatoid arthritis patients using power Doppler ultrasonography as a gold standard. Rheumatology 49:683-90

13. Bolosiu H., lonescu R., Chirieac R., Georgescu L., Rednic S., Suta M., et al. (2011) Ghidul de tratament al poliartritei reumatoide. Revista Romană de Reumatologie XX (1), 36-53

14. vanGestel A.M., Prevoo M.L., van ,t Hof M.A., van Rijswijk M.H., van de Putte L.B., van Riel P.L. (1996) Development and validation of the European League Against Rheumatism response criteria for rheumatoid arthritis. Comparison with the preliminary American College of Rheumatology and the World Health Organization/International League Against Rheumatism Criteria. Arthritis Rheum 39:34-40

15. Ma M.H., Ibrahim F., Walker D., Hassell A., Choy E.H., Kiely P.D., et al. (2012) Remission in Early Rheumatoid Arthritis: Predicting Treatment Response. J Rheumatol 39(3):470-5 